\title{
The evaluation of low-dose cytarabine in the treatment of myelodysplastic syndromes: a phase-III intergroup study
}

\author{
K. B. Miller, K. Kyungmann, F. S. Morrison, J. N. Winter, J. M. Bennett,
} R. S. Neiman, D. R. Head, P. A. Cassileth, and M. J. O'Connell

Ann Hematol (1992) 65: 162-168

In volume 65, issue No. 4 (October 1992) an original article was published by K. B. Miller et al., entitled: "The evaluation of low-dose cytarabine in the treatment of myelodysplastic syndromes: a phase-III intergroup study."

The name of the second author should have been K. Kim instead of K. Kyungmann. 